\title{
Subcellular Distribution and Metabolism Studies of the Potential Myocardial Imaging Agent $\left.{ }^{[99 \mathrm{~m}} \mathrm{Tc}(\mathrm{N})(\mathrm{DBODC})(\mathrm{PNP} 5)\right]^{+}$
}

\author{
Cristina Bolzati ${ }^{1}$, Mario Cavazza-Ceccato ${ }^{2}$, Stefania Agostini ${ }^{2}$, Shinji Tokunaga ${ }^{3}$, Dario Casara ${ }^{4}$, and Giuliano Bandoli ${ }^{2}$ \\ ${ }^{1}$ ICIS-CNR, Corso Stati Uniti, Padova, Italy; ${ }^{2}$ Department of Pharmaceutical Sciences, University of Padua, Padova, Italy; ${ }^{3}$ Research \\ Center, Nihon Medi-Physics Co., Ltd., Chiba, Japan; and ${ }^{4}$ Nuclear Medicine Service, Istituto Oncologico Veneto (IOV), Padova, Italy
}

\begin{abstract}
${ }^{99 m} \mathrm{Tc}(\mathrm{N})-\mathrm{DBODC}(5)$ is the lead compound of a new series of monocationic ${ }^{99 m} \mathrm{Tc}(\mathrm{N})$-based potential myocardial imaging agents that exhibit original biodistribution properties. This study was addressed to elucidate the mechanisms of distribution, retention, and elimination of this promising ${ }^{99 \mathrm{~m}} \mathrm{Tc}(\mathrm{N})$-agent. Methods: The sex-related in vitro and in vivo stability and the subcellular distribution of ${ }^{99 m T c}(\mathrm{~N})-\mathrm{DBODC}(5)$ were investigated. Studies were performed by considering binding to the serum proteins; stability in rat serum, human serum, and rat liver homogenates; and the chemical integrity of the complex after extraction from rat tissues such as heart, liver, and kidney, as well as from intestinal fluids and urine. The effect of cyclosporin $A$ on the in vivo pharmacokinetic properties of ${ }^{99 \mathrm{mTc}}(\mathrm{N})-\mathrm{DBODC}(5)$ was also evaluated. Subcellular distribution of ${ }^{99 \mathrm{~m} T c(N)-D B O D C(5)}$ in ex vivo rat heart was determined by standard differential centrifugation techniques. Results: No significant in vitro serum protein binding and no notable biotransformation of the native compound into different species by the in vitro action of the serum and liver enzymes was evidenced. In vivo experiments showed that sex affects the pharmacokinetic profile of the ${ }^{99 \mathrm{~m} T c}(\mathrm{~N})$-complexes including metabolism and excretion. Chromatographic profiles of $99 \mathrm{mTc}(\mathrm{N})$ radioactivity extracted from tissues and fluids of female rats were always coincident with the control. Conversely, a small percentage of metabolized species was detected by high-performance liquid chromatography in liver extracts of male rats. Furthermore, administration of cyclosporin A caused a significant reduction of lung, liver, and kidney washout along with a considerable variation in activity distribution in the intestinal tract in both male and female rats, thus indicating a possible implication of Pgp transporters in determining the biologic behavior of ${ }^{99 \mathrm{~m} T c}(\mathrm{~N})$-DBODC(5). However, this phenomenon was more pronounced in females. Subcellular distribution studies showed that $86.3 \% \pm 7.4 \%$ of ${ }^{99 m T c(N)-D B O D C(5) ~}$ was localized into mitochondrial fraction as a result of the interaction with the negative membrane potential. Conclusion: Evidence showing that the new ${ }^{99 \mathrm{~m} T c}(\mathrm{~N})$-myocardial tracers behave as multidrug resistance-associated protein P-glycoprotein substrates, combined with their selective mitochondrial accumulation, strongly supports the possibility that diagnostic application of $99 \mathrm{mTc}(\mathrm{N})-\mathrm{DBODC}(5)$ can be extended to tumor imaging and noninvasive multidrug resistance studies.
\end{abstract}

Received Feb. 8, 2008; revision accepted Apr. 22, 2008.

For correspondence contact: Cristina Bolzati, ICIS, CNR Corso Stati Uniti, 4, 35127 Padova, Italy.

E-mail: bolzati@icis.cnr.it

COPYRIGHT @ 2008 by the Society of Nuclear Medicine, Inc.
Key Words: DBODC; myocardial imaging agent; technetium; metabolism; MDR

J Nucl Med 2008; 49:1336-1344

DOI: 10.2967/jnumed.108.051482

$\mathbf{P}$ reviously, we reported a new class of nitrido ${ }^{99 \mathrm{~m}} \mathrm{Tc}$ agents of the type $\left[{ }^{99 \mathrm{~m}} \mathrm{Tc}(\mathrm{N})(\mathrm{DTC})(\mathrm{PNP})\right]^{+}$, where DTC is a dithiocarbamate ligand and PNP an aminodiphosphine ligand, as potential myocardial imaging agents (1-3). Among the tested compounds, $\left[{ }^{99 \mathrm{~m}} \mathrm{Tc}(\mathrm{N})(\mathrm{DBODC})(\mathrm{PNP} 5)\right]^{+}$ and $\left[{ }^{99 \mathrm{~m}} \mathrm{Tc}(\mathrm{N})(\mathrm{DBODC})(\mathrm{PNP} 3)\right]^{+}$(Fig. 1) $(\mathrm{DBODC}=$ bis-( $N$-ethoxyethyl)dithiocarbamato; PNP5 = bis-(dimethoxypropylphosphinoethyl)ethoxyethylamine, PNP3 = bis-(dimethoxypropylphosphinoethyl)methoxyethylamine) exhibited the most interesting biodistribution properties (3). In particular, animal studies of [99m $\mathrm{Tc}(\mathrm{N})(\mathrm{DBODC})(\mathrm{PNP} 5)]^{+}$(abbreviated $\left.{ }^{99 \mathrm{~m}} \mathrm{Tc}(\mathrm{N})-\mathrm{DBODC}(5)\right)$ revealed high and persistent myocardial uptake and rapid blood, lung, and liver clearance yielding high-quality images of the heart as early as 20 to $30 \mathrm{~min}$ after injection $(4,5)$.

Similar results were found in humans (6). Preliminary phase I studies in healthy volunteers showed that both rest and peak stress administration of ${ }^{99 \mathrm{~m}} \mathrm{Tc}(\mathrm{N})-\mathrm{DBODC}(5)$ yielded high-quality myocardial images starting 5 min after injection, thus suggesting promising diagnostic value for this tracer.

Comprehension of the biologic factors determining the pharmacokinetic behavior of these agents is crucial not only to elucidate their diagnostic importance but also to provide a rational design strategy aimed at improving the biologic properties.

This study was addressed to elucidate the mechanisms of distribution, retention, and excretion of the new cardiac ${ }^{99 \mathrm{~m}} \mathrm{Tc}(\mathrm{N})$-agents. The sex-related in vitro and in vivo stability and subcellular distribution of ${ }^{99 \mathrm{~m}} \mathrm{Tc}(\mathrm{N})-\operatorname{DBODC}(3 / 5)$ as representatives of this class of compounds were investigated. Data collected for ${ }^{99 \mathrm{~m}} \mathrm{Tc}(\mathrm{N})-\mathrm{DBODC}(3)$ were used for comparison and to confirm the metabolic pattern of ${ }^{99 \mathrm{~m}} \mathrm{Tc}(\mathrm{N})-\mathrm{DBODC}(5)$. The effect of cyclosporin A on the pharmacokinetic properties was also investigated. 


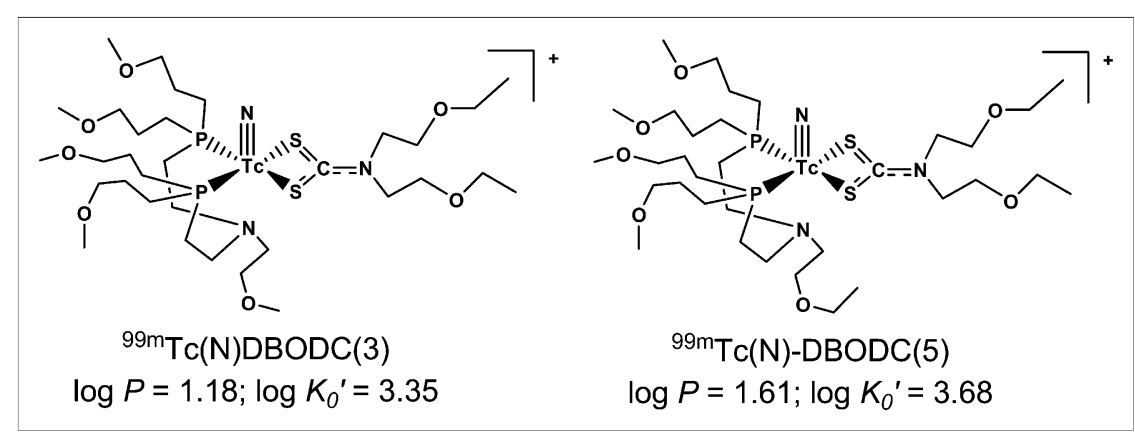

FIGURE 1. Chemical structure of the ${ }^{99 \mathrm{~m} T c}(\mathrm{~N})$-compounds, with their corresponding physical properties.

\section{MATERIALS AND METHODS}

All chemicals were purchased from Sigma-Aldrich. Solvents were of reagent grade and used without further purification. PNP3 and PNP5 were prepared according to published procedures (7). The DBODC ligand was purchased from Alchemy. $\mathrm{Na}\left[{ }^{99} \mathrm{mcO}_{4}\right]$ was eluted from a ${ }^{99} \mathrm{Mo} /{ }^{99 m} \mathrm{Tc}$ generator provided by GE Healthcare. Carbonylcyanide- $m$-chlorophenylhydrazone (CCCP), 4-(2hydroxyethyl)-1-piperazineethanesulfonic acid (HEPES), and cyclosporin A were purchased from Sigma-Aldrich.

Thin-layer chromatography (TLC) and high-performance liquid chromatography (HPLC) analyses were used to evaluate the stability of the compounds as radiochemical purity. TLC analyses were performed on $\mathrm{C}_{18} \mathrm{~F}_{254 \mathrm{~s}}$ plates (Merck) using a mixture of saline $/ \mathrm{CH}_{3} \mathrm{OH} / \mathrm{THF} / \mathrm{HAc}_{(\mathrm{g})}(2 / 8 / 1 / 1)$ as mobile phase $\left({ }^{99 \mathrm{~m}} \mathrm{Tc}(\mathrm{N})-\right.$ $\operatorname{DBODC}(3): \mathrm{R}_{f}=0.43$; $\left.{ }^{99 \mathrm{~m}} \mathrm{Tc}(\mathrm{N})-\operatorname{DBODC}(5): \mathrm{R}_{f}=0.61\right)$ and on $\mathrm{SiO}_{2} \mathrm{~F}_{254}$ plates (Merck) using a mixture of $\mathrm{EtOH} / \mathrm{CHCl}_{3} / \mathrm{Tol} /$ $\mathrm{NH}_{4} \mathrm{Ac}\left(0.5 \mathrm{~mol} \mathrm{dm}^{-1}\right)(5 / 3 / 3 / 1)\left({ }^{99 \mathrm{~m}} \mathrm{Tc}(\mathrm{N})-\mathrm{DBODC}(3): \mathrm{R}_{f}=\right.$ $\left.0.78 ;{ }^{99 \mathrm{~m}} \mathrm{Tc}(\mathrm{N})-\mathrm{DBODC}(5): \mathrm{R}_{f}=0.80\right)$. The activity on the plates was detected using a Cyclone phosphorus imaging instrument (Packard).

HPLC analysis were performed on a System Gold instrument (Beckman) equipped with programmable solvent model 126, sample injection valve $210 \mathrm{~A}$, scanning detector module 166 , and radioisotope detector model B-FC-3200 (Bioscan). HPLC analysis was performed using a reversed-phase Beckman octadecyl silane precolumn $(4.6 \times 45 \mathrm{~mm}, 5 \mu \mathrm{m})$, and a reversed-phase Beckman octadecyl silane column $(4.6 \times 250 \mathrm{~mm}, 5 \mu \mathrm{m})$. Isocratic: solvent $\mathrm{A}=$ phosphate buffer $\left(0.02 \mathrm{~mol} \mathrm{dm}{ }^{-1} ; \mathrm{pH} \mathrm{7.4}\right)$ and solvent $\mathrm{B}=$ $\mathrm{MeOH}$ (20:80); flow rate $=1 \mathrm{~mL} / \mathrm{min}$ for $30 \mathrm{~min}$; ultraviolet $\lambda=$ $215 \mathrm{~nm} ;{ }^{99 \mathrm{~m}} \mathrm{Tc}(\mathrm{N})-\mathrm{DBODC}(3) t_{r}=13.83 \mathrm{~min}$ and ${ }^{99 \mathrm{~m}} \mathrm{Tc}(\mathrm{N})-$ $\operatorname{DBODC}(5) t_{r}=18.53 \mathrm{~min}$. Serum protein binding affinity was evaluated through chromatographic methods using HPLC or a sizeexclusion MicroSpin G50 column (Amersham Biosciences). Reversed-phase HPLC was performed with a Symmetry 300 C4 precolumn $(3.9 \times 20 \mathrm{~mm}, 5 \mu \mathrm{m}$; Waters $)$ and a Symmetry $300 \mathrm{C} 4$ column $(4.6 \times 150 \mathrm{~mm}, 5 \mu \mathrm{m})$. Gradient: solvent $\mathrm{A}=\mathrm{H}_{2} \mathrm{O}(0.1 \%$ trifluoroacetic acid, $\mathrm{pH} 3)$ and solvent $\mathrm{B}=\mathrm{CH}_{3} \mathrm{CN}(0.1 \%$ trifluoroacetic acid) (0-2 min, 15\% B; 2-20 min, 65\% B; 20-22 min, 15\% B; $22-25 \mathrm{~min}, 15 \% \mathrm{~B}$ ); flow rate $=1 \mathrm{~mL} / \mathrm{min}$.

99mTc(N)-DBODC(3/5) Radiopharmaceutical Preparation

These agents were prepared in accordance with published procedures (3). Before use, the complexes were purified with a Sep-Pak C18 cartridge (Waters) conditioned with $5 \mathrm{~mL}$ of EtOH and $5 \mathrm{~mL}$ of deionized water. The reaction solution containing the ${ }^{99 \mathrm{~m}} \mathrm{Tc}(\mathrm{N})-$ complex was diluted with $8.0 \mathrm{~mL}$ of deionized water and loaded on the cartridge. Approximately $95 \%$ of the initial activity was retained on the cartridge. After washing the cartridge with water (20.0
$\mathrm{mL}$ ) and ethanol, $35 \%(5.0 \mathrm{~mL})$, the complex was eluted using an $80 / 20 \mathrm{mixture}$ of ethanol/saline $(0.250 \mathrm{~mL} \times 1 ; 0.750 \mathrm{~mL} \times 1)$. Ninety percent of the loaded activity was collected in the second fraction. The solvents were evaporated under a dinitrogen stream; the complex was dissolved in water to obtain an isotonic saline solution containing less than $5 \%(\mathrm{v} / \mathrm{v})$ ethanol and used for in vitro and in vivo studies.

The radiochemical purity of each compound, determined by TLC and HPLC techniques, was more than $98 \%$.

\section{Determination of $\log P$ and $\log K_{0}{ }^{\prime}$ Values}

$\log P$ values were determined by vortex mixing $(20 \mathrm{~min}) 3 \mathrm{~mL}$ of $n$-octanol, $3 \mathrm{~mL}$ of phosphate buffer ( $\left.0.02 \mathrm{~mol} \mathrm{dm}^{-1}, \mathrm{pH} 7.4\right)$, and $100 \mu \mathrm{L}$ of the ${ }^{99 \mathrm{~m}} \mathrm{Tc}(\mathrm{N})$-radiolabeled compounds purified by HPLC chromatography and treated with a Sep-Pak C18 cartridge as indicated above. After centrifugation $(3,000 \mathrm{~g}$ for $10 \mathrm{~min})$, aliquots (100 $\mu \mathrm{L}$; in triplets) of both the organic and the aqueous phases were collected and counted with a $\gamma$-counter. The $P$ values were calculated using the following equation: $P=$ (activity concentration in $n$-octanol)/(activity concentration in aqueous solution).

$\log K_{0}{ }^{\prime}$ values of the radiolabeled compounds were measured using the previously reported method (3). For comparison, the log $P$ and $\log K_{0}{ }^{\prime}$ values of ${ }^{99 \mathrm{~m}}$ Tc-sestamibi were determined.

\section{In Vitro Studies}

Protein Binding. The affinity of the ${ }^{99 \mathrm{~m}} \mathrm{Tc}(\mathrm{N})$-complexes toward the serum proteins was evaluated by chromatographic methods, using the procedures reported below.

In a propylene test tube, $100 \mu \mathrm{L}$ of the purified complex (50-100 $\mathrm{MBq}$ ) were added to $900 \mu \mathrm{L}$ of human or rat serum; at 2, 10, and 60 min of incubation at $37^{\circ} \mathrm{C}, 150 \mu \mathrm{L}$ of each sample were withdrawn and diluted in $1.350 \mathrm{~mL}$ of phosphate buffer (phosphate-buffered saline, $0.02 \mathrm{~mol} \mathrm{dm}^{-1}, \mathrm{pH}$ 7.4). Aliquots of this solution were treated and analyzed. In method A, $100 \mu \mathrm{L}$ were analyzed by HPLC, without further purification, using a reversed-phase Symmetry C4 column. In method B, $25 \mu \mathrm{L}$ were loaded on a prespun (735g for $1 \mathrm{~min}$ ) size-exclusion MicroSpin G50 column). The column was centrifuged at $735 \mathrm{~g}$ for $1 \mathrm{~min}$. The collected eluate and the column were counted in a $\gamma$-counter. The protein-bound complex was calculated as the percentage of the total activity. Twentyfive microliters of ${ }^{99 \mathrm{~m}} \mathrm{Tc}$-complex were controlled after incubation in phosphate-buffered saline at $37^{\circ} \mathrm{C}$ as a blank. As a control, a small fraction of the collected eluate was analyzed by HPLC. The chromatographic profiles revealed the presence of only the protein fraction. All activity was associated with the mini column.

Metabolism. For incubation in liver homogenates, the organs freshly excised from female and male rats were rapidly rinsed and 
homogenized in $20 \mathrm{mM}$ HEPES buffer $(\mathrm{pH} 7.3)$ with an UltraTurrax T25 homogenator (IKA Works, Inc.) for $1 \mathrm{~min}$ at $4{ }^{\circ} \mathrm{C}$.

The in vitro metabolism of the agents was evaluated by monitoring the radiochemical purity at different time points using the following procedure. In a propylene test tube, $50 \mu \mathrm{L}$ of the purified ${ }^{99 \mathrm{~m}} \mathrm{Tc}$-complex $(50-100 \mathrm{MBq})$ were added to $950 \mu \mathrm{L}$ of rat serum, $950 \mu \mathrm{L}$ of human serum, $950 \mu \mathrm{L}$ of fresh $30 \%$ liver homogenate, and $950 \mu \mathrm{L}$ of saline and HEPES buffer as a blank. The samples were incubated at $37^{\circ} \mathrm{C}$ for $24 \mathrm{~h}$. Aliquots $(200 \mu \mathrm{L})$ of each solution were withdrawn, diluted with $800 \mu \mathrm{L}$ of phosphate buffer $(0.2 \mathrm{~mol}$ $\mathrm{dm}^{-1}, \mathrm{pH}$ 7.4), and treated using an OASIS hydrophilic lipophilic balance (HLB) extraction cartridge (Waters) before HPLC injection. In detail, the sample was loaded on cartridges, conditioned with $\mathrm{MeOH}(1 \mathrm{~mL})$, equilibrated with water $(1 \mathrm{~mL})$, and washed with $\mathrm{MeOH} 5 \%$ (3 mL). Ninety percent of the starting activity was eluted using a 90/10 mixture of EtOH and saline ( $1 \mathrm{~mL})$. Aliquots of this fraction were analyzed by TLC and HPLC.

\section{Animal Studies}

Animal experiments were performed in compliance with the relevant national laws relating to the conduct of animal experimentation. Studies were performed on both female and male SpragueDawley rats.

Biodistribution. The animals were anesthetized with an intraperitoneal injection of a mixture of zolazepam $\mathrm{HCl}$ plus tiletamine $\mathrm{HCl}$ (Zoletil; Virbac [40 $\mathrm{mg} \mathrm{kg}^{-1}$ ]) and xylazine $\left(2 \mathrm{mg} \mathrm{kg}^{-1}\right)$. A $150-\mu \mathrm{L}$ dose of the radioactive complex $(300-370 \mathrm{kBq})$ was injected through the jugular vein. At different times after injection, animals $(n=3)$ were sacrificed. A blood sample and the excised organs rinsed with saline were weighed and counted in a $\gamma$-counter. Results were normalized as percentage injected dose per gram.

In Vivo Stability. The complexes were extracted from the rat tissues and urine using the following procedure. A $150-\mu \mathrm{L}$ dose of radioactive compound (370-500 MBq) was injected through the jugular vein in anesthetized rats. At 30 and 120 min after injection, animals $(n=3)$ were sacrificed. The heart and the metabolic organs and tissues were excised, rinsed, weighed, and counted.

Extraction of ${ }^{99 m} T c(N)-D B O D C(3 / 5)$ from Heart. The excised heart was placed in saline $(2 \mathrm{~mL})$, chopped for $5 \mathrm{~min}$, and centrifuged $(3,000 \mathrm{~g}$ for $10 \mathrm{~min})$. Pellet and supernatant were counted for their radioactivity content; only $15 \%$ of the initial activity was found in the liquid fraction. The remaining activity was completely extracted from the tissue by treating the pellet with $\mathrm{MeCN}(2 \mathrm{~mL})$ and chopping for 5 additional minutes. The organic solution was separated from the particulate by centrifugation (3,000 $\mathrm{g}$ for $10 \mathrm{~min})$. Aliquots of the aqueous and organic solutions, the latter previously diluted 1:3 with water, were eluted through an OASIS HLB extraction cartridge and analyzed by TLC and HPLC as described before.

Extraction of ${ }^{99 m} T c(N)-D B O D C(3 / 5)$ from Liver and Kidneys. The extraction was performed as described above, and the eluate analyzed by TLC and HPLC.

Metabolites in Intestine. The intestinal lumen was rinsed with $2 \mathrm{~mL}$ of saline; $90 \%$ of the total activity was collected in the endoluminal content. The liquid fraction was separated from the intestinal content by centrifugation $(3,000 \mathrm{~g}$ for $10 \mathrm{~min}$ ) and counted. Fifty percent of the activity was found in this first liquid fraction. Exhaustive extraction of the residual activity from the solid fraction was performed by using $\mathrm{MeCN}(2 \mathrm{~mL})$ followed by centrifugation $(3,000 \mathrm{~g}$ for $10 \mathrm{~min})$. An aliquot of each fraction
( $1 \mathrm{~mL}$ ) was eluted through an OASIS HLB extraction cartridge, and the eluate analyzed by TLC and HPLC.

Metabolites in Urine. Urine was collected directly from the bladder and loaded onto an activated OASIS HLB extraction cartridge. The complex was eluted and analyzed by TLC and HPLC.

The method used to extract metabolites from tissues and fluids allowed for the recovery and analysis about $90 \%$ of the activity.

Effects of Cyclosporin A on Pharmacokinetic Properties of ${ }^{99 m} \operatorname{Tc}(N)-D B O D C(5)$. Animals $(n=6)$ were treated with a solution of cyclosporin A $\left(16 \mathrm{mg} \mathrm{kg}^{-1}\right.$ in $250 \mu \mathrm{L}$ of dimethyl sulfoxide intraperitoneally) $60 \mathrm{~min}$ before the radiotracer administration. At 30 and 120 min after injection, animals $(n=3)$ were sacrificed. As a blank, a group of animals $(n=6)$ received the carrier vehicle solution (dimethyl sulfoxide) by intraperitoneal injection $60 \mathrm{~min}$ before radiotracer administration.

Subcellular Distribution. Subcellular distribution of ${ }^{99 \mathrm{~m}} \mathrm{Tc}(\mathrm{N})-$ DBODC(5) was evaluated in ex vivo myocardial tissue, excised 15 min after injection, by applying a previously reported procedure (8). For comparison, the subcellular distributions of ${ }^{99 \mathrm{~m} T c-s e s t a m i b i}$ and ${ }^{99 \mathrm{~m}} \mathrm{Tc}$-tetrofosmin were assessed in the same experiment.

${ }^{99 m} \mathrm{Tc}$-activity in each supernatant and pellet was measured in a $\gamma$-counter.

Malate dehydrogenase, a mitochondrial inner matrix enzyme, was used as a marker to determine the distribution and association of mitochondrial contents into various fractions (9).

CCCP experiments (final concentration, $5 \mu \mathrm{mol} \mathrm{dm}{ }^{-1}$ ) were performed to define the accumulation of ${ }^{99 \mathrm{~m}} \mathrm{Tc}$-complexes in the intact mitochondria dispersed into each fraction. CCCP, in fact, uncouples the influx of protons from ATP synthesis, inducing a collapse of the mitochondrial membrane potential, resulting in release of activity from the mitochondrial pellet in the cytosolic fractions (supernatants) $(8,10,11)$.

\section{RESULTS}

${ }^{99 m} \mathrm{Tc}(\mathrm{N})-\mathrm{DBODC}(3 / 5)$ complexes were prepared using the classic 2-step procedure and purified by Sep Pak C18 filtration (3). This process was needed to remove some radioimpurities before testing the compounds in biologic studies and to avoid any interference from the contaminants.

Measures of the $\log P$ and $\log K_{0}{ }^{\prime}$ values of ${ }^{99 m}$ Tc-agents revealed that ${ }^{99 \mathrm{~m}} \mathrm{Tc}(\mathrm{N})-\mathrm{DBODC}(3 / 5)$ complexes were more lipophilic than $99 \mathrm{~m}$ Tc-sestamibi. Staring from the more lipophilic compound, the corresponding $\log P$ and $\log K_{0}{ }^{\prime}$ values were as follows: ${ }^{99 \mathrm{~m}} \mathrm{Tc}(\mathrm{N})-\mathrm{DBODC}(5): \log P=1.61 \pm$ $0.12, \log K_{0}{ }^{\prime}=3.68 \pm 0.05 ;{ }^{99 \mathrm{~m}} \mathrm{Tc}(\mathrm{N})-\mathrm{DBODC}(3): \log P=$ $1.18 \pm 0.15, \log K_{0}{ }^{\prime}=3.35 \pm 0.22 ;{ }^{99 \mathrm{~m} T c-s e s t a m i b i:} \log$ $P=0.87 \pm 0.18, \log K_{0}{ }^{\prime}=3.22 \pm 0.08$.

Because of the fast blood clearance and the low liver uptake followed by rapid washout (Table 1), ${ }^{99 \mathrm{~m}} \mathrm{Tc}(\mathrm{N})$-tracer stability was first estimated in vitro. Thus, binding to the serum proteins and biotransformation of the two agents in blood and liver tissues were assessed by incubating the purified compounds at $37^{\circ} \mathrm{C}$ in human and rat serum and in rat liver homogenates.

The affinity of the complexes toward the serum proteins was evaluated at 2, 10, and $60 \mathrm{~min}$ by chromatographic methods using reversed-phase HPLC chromatography 
TABLE 1

Baseline Biodistribution

\begin{tabular}{|c|c|c|c|c|c|c|}
\hline \multirow[b]{2}{*}{ Group* } & \multirow[b]{2}{*}{ Organ } & \multicolumn{5}{|c|}{$\%$ dose $/ g$ for 3 rats (mean $\pm S D$ ) } \\
\hline & & $2 \min$ & $10 \mathrm{~min}$ & $30 \mathrm{~min}$ & $60 \min$ & $120 \mathrm{~min}$ \\
\hline \multirow[t]{10}{*}{ A } & Blood & $0.13 \pm 0.04$ & $0.03 \pm 0.02$ & $0.02 \pm 0.00$ & $0.02 \pm 0.01$ & $0.01 \pm 0.00$ \\
\hline & Heart & $2.85 \pm 0.09$ & $2.82 \pm 0.05$ & $3.01 \pm 0.30$ & $2.98 \pm 0.04$ & $2.82 \pm 0.04$ \\
\hline & Lungs & $1.18 \pm 0.06$ & $0.63 \pm 0.04$ & $0.55 \pm 0.02$ & $0.59 \pm 0.01$ & $0.34 \pm 0.02$ \\
\hline & Liver & $1.53 \pm 0.29$ & $0.43 \pm 0.12$ & $0.18 \pm 0.02$ & $0.10 \pm 0.01$ & $0.06 \pm 0.01$ \\
\hline & Kidneys & $8.54 \pm 0.12$ & $7.32 \pm 0.09$ & $4.86 \pm 0.04$ & $4.05 \pm 0.06$ & $2.87 \pm 0.02$ \\
\hline & Small intestine & $11.01 \pm 0.52$ & $15.21 \pm 1.94$ & $6.22 \pm 0.39$ & $7.45 \pm 0.12$ & $15.51 \pm 0.29$ \\
\hline & Muscle & $0.21 \pm 0.02$ & $0.25 \pm 0.04$ & $0.26 \pm 0.03$ & $0.32 \pm 0.02$ & $0.38 \pm 0.03$ \\
\hline & Urine & - & - & $7.41 \pm 0.53$ & - & $20.51 \pm 0.56$ \\
\hline & Heart-to-lung ratio & 2.41 & 4.47 & 5.47 & 5.05 & 8.35 \\
\hline & Heart-to-liver ratio & 1.86 & 6.55 & 16.72 & 29.80 & 47.00 \\
\hline \multirow[t]{10}{*}{ B } & Blood & $0.14 \pm 0.05$ & $0.03 \pm 0.01$ & $0.02 \pm 0.00$ & $0.02 \pm 0.01$ & $0.01 \pm 0.00$ \\
\hline & Heart & $2.95 \pm 0.09$ & $2.84 \pm 0.05$ & $3.02 \pm 0.30$ & $2.91 \pm 0.04$ & $2.75 \pm 0.04$ \\
\hline & Lungs & $0.88 \pm 0.06$ & $0.64 \pm 0.05$ & $0.57 \pm 0.02$ & $0.39 \pm 0.01$ & $0.29 \pm 0.02$ \\
\hline & Liver & $2.53 \pm 0.25$ & $1.43 \pm 0.12$ & $0.64 \pm 0.02$ & $0.20 \pm 0.01$ & $0.11 \pm 0.01$ \\
\hline & Kidneys & $14.12 \pm 1.25$ & $10.12 \pm 1.51$ & $6.70 \pm 0.98$ & $5.98 \pm 0.68$ & $3.32 \pm 0.21$ \\
\hline & Small intestine & $5.97 \pm 2.52$ & $9.59 \pm 1.02$ & $6.22 \pm 0.50$ & $6.57 \pm 1.39$ & $6.91 \pm 2.39$ \\
\hline & Muscle & $0.23 \pm 0.03$ & $0.21 \pm 0.01$ & $0.18 \pm 0.02$ & $0.15 \pm 0.01$ & $0.16 \pm 0.05$ \\
\hline & Urine & - & - & $0.57 \pm 0.09$ & - & $16.61 \pm 1.40$ \\
\hline & Heart-to-lung ratio & 3.35 & 4.44 & 5.29 & 7.46 & 9.48 \\
\hline & Heart-to-liver ratio & 1.16 & 1.98 & 4.71 & 14.55 & 25.00 \\
\hline \multirow[t]{10}{*}{ C } & Blood & $0.31 \pm 0.03$ & $0.15 \pm 0.01$ & $0.12 \pm 0.02$ & $0.06 \pm 0.00$ & $0.15 \pm 0.01$ \\
\hline & Heart & $3.09 \pm 0.22$ & $3.17 \pm 0.30$ & $3.00 \pm 0.21$ & $2.99 \pm 0.03$ & $2.72 \pm 0.19$ \\
\hline & Lungs & $1.83 \pm 0.02$ & $1.16 \pm 0.07$ & $0.74 \pm 0.02$ & $0.56 \pm 0.23$ & $0.62 \pm 0.06$ \\
\hline & Liver & $2.21 \pm 0.03$ & $1.43 \pm 0.30$ & $0.88 \pm 0.08$ & $0.53 \pm 0.04$ & $0.63 \pm 0.09$ \\
\hline & Kidneys & $14.91 \pm 1.20$ & $11.59 \pm 0.98$ & $7.83 \pm 0.13$ & $6.87 \pm 0.05$ & $5.69 \pm 1.25$ \\
\hline & Small intestine & $1.51 \pm 0.17$ & $8.05 \pm 1.21$ & $8.96 \pm 1.75$ & $11.21 \pm 0.87$ & $12.14 \pm 4.17$ \\
\hline & Muscle & $0.30 \pm 0.03$ & $0.30 \pm 0.04$ & $0.36 \pm 0.08$ & $0.30 \pm 0.10$ & $0.38 \pm 0.05$ \\
\hline & Urine & - & $14.35 \pm 4.18$ & $12.78 \pm 4.22$ & - & $16.51 \pm 1.44$ \\
\hline & Heart-to-lung ratio & 1.69 & 2.74 & 4.04 & 5.39 & 4.38 \\
\hline & Heart-to-liver ratio & 1.40 & 2.22 & 3.39 & 5.69 & 4.30 \\
\hline
\end{tabular}

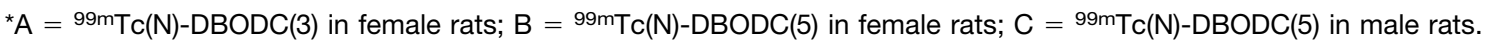

(reversed-phase Symmetry C4 300 column) and size-exclusion chromatography (MicroSpin columns).

Figure 2 shows HPLC analysis of ${ }^{99 \mathrm{~m}} \mathrm{Tc}(\mathrm{N})-\mathrm{DBODC}(3 / 5)$ incubated in human serum. Each analysis displays 2 profiles, one resulting from ultraviolet detection of the serum proteins and the other from radiometric detection of ${ }^{99 m} \mathrm{Tc}(\mathrm{N})$ complexes. No ${ }^{99 \mathrm{~m}} \mathrm{Tc}$-activity was coeluted with any of the protein fraction, and essentially all activity was eluted in a single peak as ${ }^{99 \mathrm{~m}} \mathrm{Tc}(\mathrm{N})-\mathrm{DBODC}(3 / 5)$ complex. These observations established that, under these conditions, there was no detectable binding to serum components.

These findings were confirmed by size-exclusion chromatographic experiments. The percentage of free compound, evaluated after 2 and $60 \mathrm{~min}$ of incubation, was $98.56 \pm 0.56$ and $95.00 \pm 0.71$, respectively, for ${ }^{99 \mathrm{~m}} \mathrm{Tc}(\mathrm{N})-$ $\operatorname{DBODC}(3)$ and $99.02 \pm 0.78$ and $93.01 \pm 0.14$, respectively, for ${ }^{99 \mathrm{~m}} \mathrm{Tc}(\mathrm{N})-\mathrm{DBODC}(5)$.

These results indicated that ${ }^{99 \mathrm{~m}} \mathrm{Tc}(\mathrm{N})-\mathrm{DBODC}(3)$ and ${ }^{99 \mathrm{~m}} \mathrm{Tc}(\mathrm{N})-\mathrm{DBODC}(5)$ simply were distributed from the blood flow as free cations or that an extremely labile conjugation between the serum proteins and the complex could be involved, such that the ${ }^{99 \mathrm{~m}} \mathrm{Tc}(\mathrm{N})-\mathrm{DBODC}(3 / 5)$ dissociated during the elution.

In vitro metabolism studies performed in human and rat serum, as well as in rat liver homogenates, revealed that the radiolabeled compounds remain intact for prolonged incubation at $37^{\circ} \mathrm{C}$.

The quantitative organ biodistribution of ${ }^{99 \mathrm{~m}} \mathrm{Tc}(\mathrm{N})-$ $\operatorname{DBODC}(3 / 5)$ is reported in Table 1.

Data show high and persistent myocardial uptake in both female and male rats. However, washout of ${ }^{99 m} \mathrm{Tc}(\mathrm{N})-$ DBODC(5) from nontarget tissues, such as lungs, liver, and kidneys, was remarkably higher in female than in male rats; as a consequence, the heart-to-lung and heart-to-liver ratios were found to decrease in male rats.

The distribution of ${ }^{99 \mathrm{~m}} \mathrm{Tc}(\mathrm{N})-\mathrm{DBODC}(5)$ activity in principal organs with or without cyclosporin A administration is reported in Table 2 and Figure 3. The effects of cyclosporin A on the pharmacokinetic profile were evident at 30 and 120 min after injection. Notable reductions in lung, liver, and kidney washout (Figs. 3A and 3B) and significant variations in the activity distribution in the intestinal tract (Figs. 3C and 
FIGURE 2. HPLC profiles of $99 \mathrm{mTc}(\mathrm{N})$ $\operatorname{DBODC}(3 / 5)$ incubated at $37^{\circ} \mathrm{C}$ for 60 min in human serum. HS = ultraviolet trace of human serum detected at 215

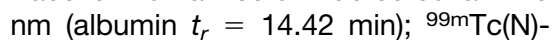
$\mathrm{DBODC}(3) t_{r}=18.9 \mathrm{~min} ; 99 \mathrm{mTc}(\mathrm{N})-$ $\operatorname{DBODC}(5) t_{r}=19.76 \mathrm{~min}$. Superimposable HPLC profiles were obtained at 2 min. Similar results were observed in rat serum.

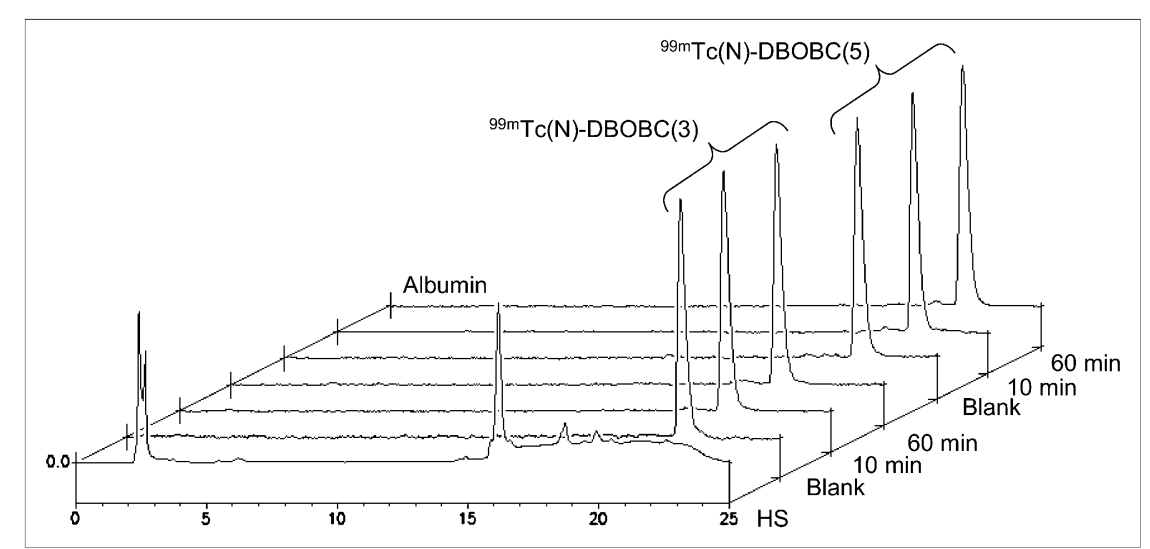

3D) were observed. No variation in the biodistribution profile of ${ }^{99 \mathrm{~m}} \mathrm{Tc}(\mathrm{N})$-DBODC(5) was observed after administration of a dimethyl sulfoxide by intraperitoneal injection 60 min before radiotracer.

Activity localized in the heart and other tissues or fluids after intravenous injection of ${ }^{99 \mathrm{~m}} \mathrm{Tc}(\mathrm{N})$-complexes was extracted using the procedure reported in the experimental section. Compared with homogenization, chopping maintained superior cell integrity. The initial soft treatment with saline extracted approximately $15 \%$ of the starting activity, corresponding to unbound activity localized in the extracellular space and on the cellular surface through weak interactions. Exhaustive discharge of the ${ }^{99 \mathrm{~m}} \mathrm{Tc}$-activity was achieved using pure $\mathrm{MeCN}$ because of its ability to denature biologic structures such as proteins and phospholipidic bilayers and to dissolve the lipophilic compound.

TLC and HPLC analysis was performed on the recovered aqueous and organic solutions to investigate the effect of the uptake process on the chemical identity of the complex. The chromatographic profiles shown in Figures $4 \mathrm{~B}$ and $4 \mathrm{C}$ demonstrated that the myocardial uptake process and the corresponding trapping mechanism do not involve any change in the chemical nature of the tracer (control peak, Fig. 4A). Similarly, the activity extracted from other tissues and fluids in female rats at 30 and 120 min after injection evidenced that the radiotracer was stable in vivo.

On the contrary, the HPLC profiles of the activity recovered from male liver and intestinal fluids showed, at $120 \mathrm{~min}$ after injection, the presence of a low amount $(<10 \%)$ of undetermined hydrophilic compounds (Figs. 4D and 4E), consistent with the higher expression of hepatic cytochrome P450 enzymes in male than in female rats $(12,13)$. However, no change of tracer identity was found in the kidneys and urine of male rats (Figs. 4F and 4G).

Subcellular distribution studies of ${ }^{99 \mathrm{~m}} \mathrm{Tc}(\mathrm{N})-\operatorname{DBODC}(5)$ were performed by standard differential centrifugation techniques using the commercially available compounds as a control ( ${ }^{99 \mathrm{~m}} \mathrm{Tc}$-sestamibi and ${ }^{99 \mathrm{~m}} \mathrm{Tc}$-tetrofosmin) (8). For all complexes, most activity was released in supernatants I and II (defined as the two cytosolic fractions isolated during the

TABLE 2

Sex-Related Effects of Cyclosporine A on Biodistribution Profile of ${ }^{99 m T c}(\mathrm{~N})-\mathrm{DBODC}(5)$

$\%$ dose/g for 3 rats (mean $\pm S D$ )

\begin{tabular}{|c|c|c|c|c|c|c|c|c|}
\hline \multirow{2}{*}{ Organ } & \multicolumn{2}{|c|}{ Female (baseline) } & \multicolumn{2}{|c|}{ Female (cyclosporin A) } & \multicolumn{2}{|c|}{ Male (baseline) } & \multicolumn{2}{|c|}{ Male (cyclosporin A) } \\
\hline & $30 \mathrm{~min}$ & $120 \mathrm{~min}$ & $30 \mathrm{~min}$ & $120 \mathrm{~min}$ & $30 \mathrm{~min}$ & $120 \mathrm{~min}$ & $30 \mathrm{~min}$ & $120 \mathrm{~min}$ \\
\hline Blood & $0.02 \pm 0.00$ & $0.01 \pm 0.00$ & $0.03 \pm 0.01$ & $0.01 \pm 0.00$ & $0.12 \pm 0.02$ & $0.15 \pm 0.01$ & $0.12 \pm 0.03$ & $0.05 \pm 0.01$ \\
\hline Heart & $3.02 \pm 0.30$ & $2.75 \pm 0.04$ & $3.51 \pm 0.19$ & $3.50 \pm 0.20$ & $3.00 \pm 0.21$ & $2.72 \pm 0.19$ & $3.71 \pm 0.51$ & $3.51 \pm 0.09$ \\
\hline Lungs & $0.57 \pm 0.13$ & $0.29 \pm 0.02$ & $0.91 \pm 0.05$ & $0.54 \pm 0.03$ & $0.74 \pm 0.02$ & $0.62 \pm 0.06$ & $1.64 \pm 0.41$ & $0.76 \pm 0.16$ \\
\hline Liver & $0.64 \pm 0.02$ & $0.11 \pm 0.01$ & $0.72 \pm 0.06$ & $0.69 \pm 0.11$ & $0.88 \pm 0.08$ & $0.63 \pm 0.09$ & $2.83 \pm 0.10$ & $1.80 \pm 0.60$ \\
\hline Kidneys & $6.70 \pm 0.98$ & $3.32 \pm 0.21$ & $8.21 \pm 0.98$ & $9.57 \pm 0.89$ & $7.83 \pm 0.13$ & $5.69 \pm 1.25$ & $13.82 \pm 1.00$ & $12.96 \pm 2.46$ \\
\hline Small intestine & $6.22 \pm 0.50$ & $6.91 \pm 2.39$ & $9.78 \pm 0.58$ & $15.08 \pm 2.09$ & $8.96 \pm 1.75$ & $12.14 \pm 4.17$ & $10.65 \pm 1.32$ & $8.02 \pm 1.63$ \\
\hline Intestinal tissue* & $7.80 \pm 0.39$ & $8.92 \pm 2.00$ & $59.86 \pm 10.39$ & $44.65 \pm 1.48$ & $66.33 \pm 0.65$ & $61.51 \pm 9.21$ & $63.64 \pm 10.90$ & $28.18 \pm 4.57$ \\
\hline Endoluminal $^{*}$ & $92.00 \pm 0.39$ & $90.05 \pm 2.00$ & $40.14 \pm 10.39$ & $55.35 \pm 1.48$ & $33.67 \pm 0.65$ & $38.49 \pm 9.21$ & $36.36 \pm 10.90$ & $71.82 \pm 4.57$ \\
\hline Urine & $0.57 \pm 0.09$ & $16.61 \pm 1.40$ & $8.94 \pm 0.29$ & $8.27 \pm 3.40$ & $12.78 \pm 4.22$ & $14.82 \pm 1.44$ & NA & $16.91 \pm 2.59$ \\
\hline $\begin{array}{l}\text { Heart-to-lung } \\
\text { ratio }\end{array}$ & 5.29 & 9.48 & 3.85 & 6.48 & 4.04 & 4.38 & 2.26 & 4.62 \\
\hline $\begin{array}{l}\text { Heart-to-liver } \\
\text { ratio }\end{array}$ & 4.71 & 25.00 & 4.87 & 5.07 & 3.39 & 4.30 & 1.31 & 1.95 \\
\hline
\end{tabular}

${ }^{*}$ As relative percentage of total small-intestinal activity.

$\mathrm{NA}=$ data not available. 

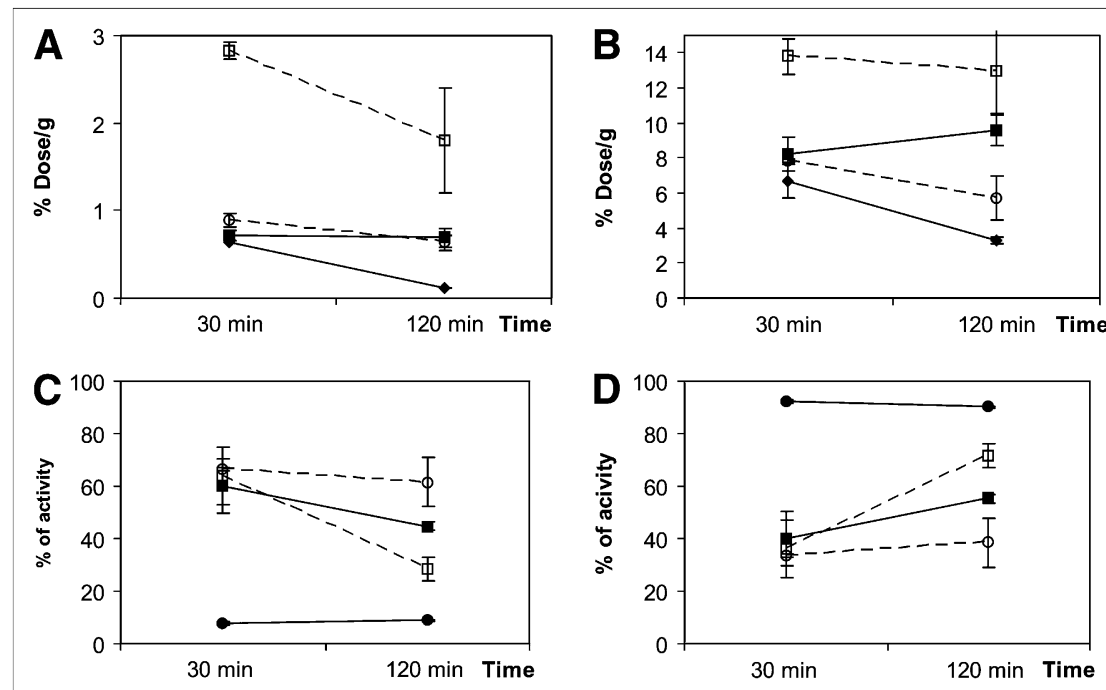

FIGURE 3. Time-activity curves of liver $(A)$, kidneys $(B)$, intestinal tissue $(C)$, and endoluminal content (D) before (baseline) and after cyclosporin A administration for female, baseline ( $\mathbf{O})$; female, cyclosporin A (घ); male, baseline (O); and male, cyclosporin A ( $\square$ ). fractionation process), and only a small portion of the activity was found associated with the mitochondrial fraction (Fig. 5A).

A correlative evaluation of supernatants and pellets with the presence of malate dehydrogenase and ${ }^{99 \mathrm{~m}} \mathrm{Tc}$-activity is reported in Figures 5B and 5C. Approximately 80\% of malate dehydrogenase was found in the cytosolic fractions and directly correlated with ${ }^{99 \mathrm{~m}}$ Tc-activity, thus indicating that the procedure damaged the mitochondrial structure, allowing leakage of inner matrix enzyme content (8). Addition of the mitochondrial uncoupler CCCP to supernatants, 3 min before centrifugation of the cell fragment pellet or mitochondrial pellet, determined a significant reduction of $99 \mathrm{~m}$ Tc-activity associated with the pellets (Fragment: $1.64 \pm 0.30$ vs. $0.30 \pm 0.19 ; 7.08 \pm 0.88$ vs. $1.95 \pm 0.65$ Mitochondria: $3.15 \pm 2.03$ vs. $0.41 \pm 0.45 ; 8.66 \pm 3.14$ vs. $1.76 \pm 1.07$ for ${ }^{99 \mathrm{~m}} \mathrm{Tc}$-sestamibi and ${ }^{99 \mathrm{~m}} \mathrm{Tc}(\mathrm{N})-\operatorname{DBODC}(5)$, respectively.) (Fig. 6).

CCCP-releasable ${ }^{99 \mathrm{~m}}$ Tc-activity was present in both pellets, revealing the presence of viable mitochondria in the cell membrane fraction.
The corrected subcellular distribution of the complexes was estimated by correlating the distribution of the markers with the mitochondrial integrity. The result is reported in Figure 7.

As an additional control, TLC analysis of the activity recovered in the heart homogenate and in supernatant I was performed, and only 1 radioactive spot corresponding to intact ${ }^{99 \mathrm{~m}} \mathrm{Tc}(\mathrm{N})-\mathrm{DBODC}(5)$ was observed.

\section{DISCUSSION}

It is commonly maintained that the presence of lateral ether groups on cationic ${ }^{99 \mathrm{~m}} \mathrm{Tc}$-complexes decreases proteinbinding capability and hepatic accumulation and favors a fast clearance from these regions. These behaviors were particularly evident in the pharmacokinetic profiles of ${ }^{99 \mathrm{~m}} \mathrm{Tc}(\mathrm{N})-\mathrm{DBODC}(3 / 5)$ agents.

Despite the presence of similar ether groups on their coordination sphere and the higher lipophilic character of both ${ }^{99 m} \mathrm{Tc}(\mathrm{N})-\mathrm{DBODC}(3 / 5)$ complexes, their pharmacokinetic

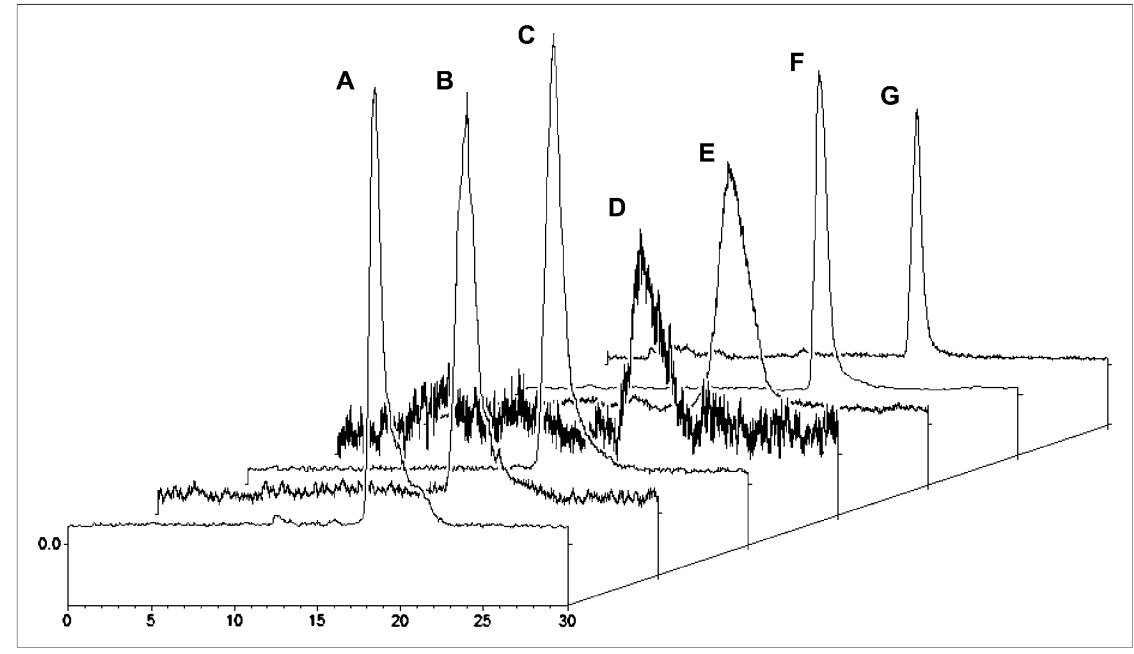

FIGURE 4. HPLC profiles of ${ }^{99 m T c(N)-~}$ DBODC(5) complexes after tissue extraction at $120 \mathrm{~min}$ after injection. Peaks represent control $(A)$; activity extracted from myocardial tissue after treatment with saline $(\mathrm{B})$ or treatment with $\mathrm{MeCN}$ (C); and activity extracted with $\mathrm{MeCN}$ from liver (D), endoluminal content (E), kidneys $(F)$, and directly from urine $(G)$ of male rats. No hepatic biotransformation of tracers was observed at 30 min after injection. No changes in tracer identity were found in tissues and fluids of female rats at 30 and $120 \mathrm{~min}$ after injection. Similar results were observed for 99mTc(N)-DBODC(3). 
FIGURE 5. (A) Percentage of distribution of $99 \mathrm{~m} T \mathrm{c}$-activity in fractions obtained from isolated rat hearts, with values expressed as percentage of total recoverable activity. (B) Percentage of distribution of malate dehydrogenase activity in each tissue fraction. (C) Correlative ${ }^{99 m}$ Tc-activity and malate dehydrogenase content in "cytosolic" fractions.

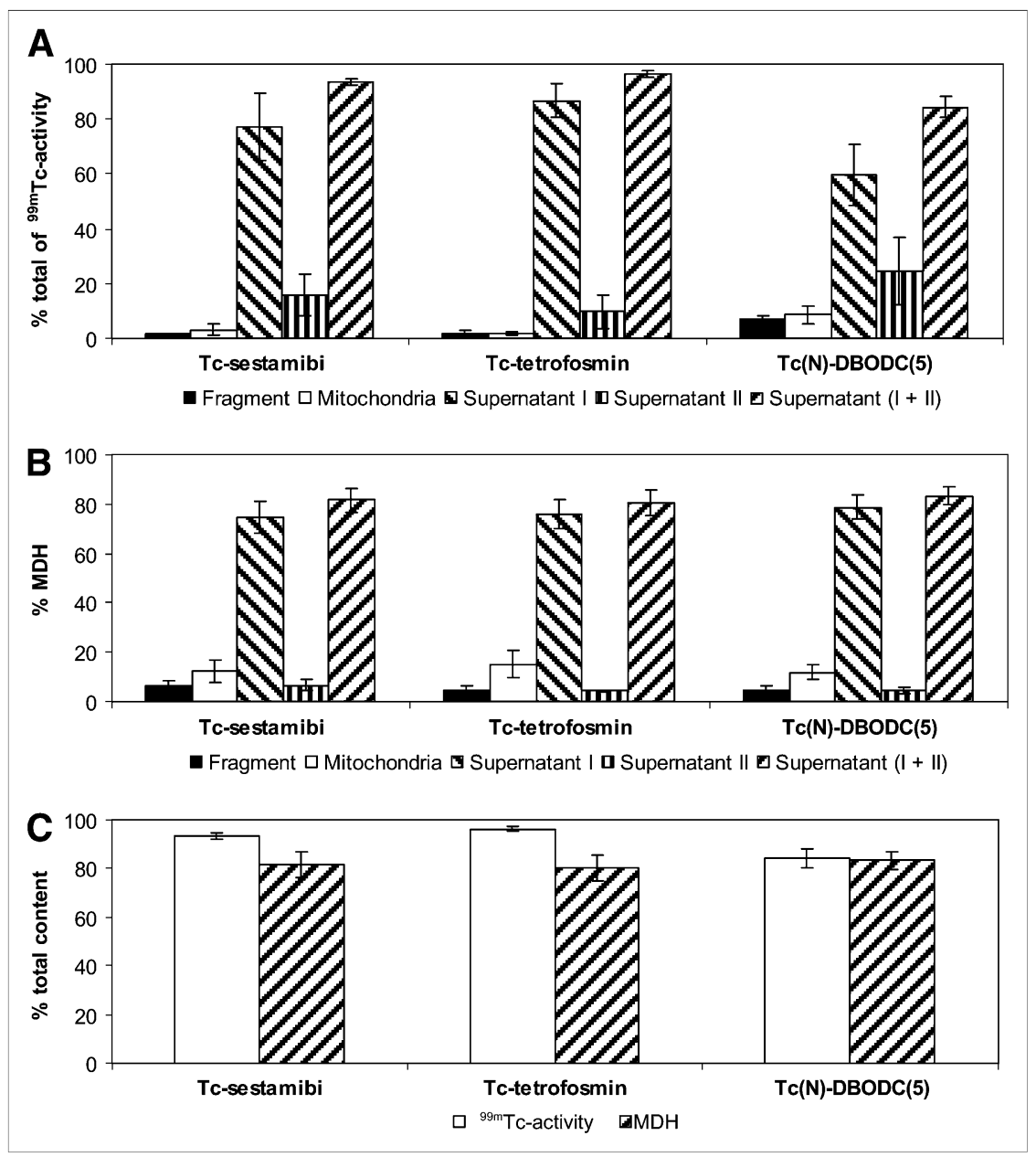

properties were significantly different from those of ${ }^{99 \mathrm{~m}} \mathrm{Tc}-$ sestamibi and ${ }^{99 \mathrm{~m}} \mathrm{Tc}$-tetrofosmin (3-5).

In particular, the excreted activity quickly moved from the hepatic tissue to the intestinal area, showing a high accumulation in this region also at $10 \mathrm{~min}$ after injection. The high intestinal accumulation may also account for the fast decrease of activity in the circulation and, consequently, in nontarget tissues, resulting in remarkably high heart-to-liver and heart-to-lung ratios.

The results presented here clearly show that metabolism of these ${ }^{99 \mathrm{~m}} \mathrm{Tc}(\mathrm{N})$-complexes cannot explain their pharmacokinetic properties (3-5). Specifically, experimental data appear to support an important role played by P-glycoproteins (Pgp) or multidrug resistance-associated protein (MDR)-Pgp on the rapid elimination of these lipophilic compounds from the tissues (14-17).

Protein-binding studies demonstrated a negligible association with serum proteins, in agreement with the extremely fast in vivo distribution of the complexes characterized by a rapid blood clearance.

Biodistribution studies performed on both female and male rats showed high and prolonged heart uptake. Differences between the observed values of heart uptake reported here in female rats and previous data in the literature $(2,3,18)$ could be attributed to differences in the composition of the injected solution. In particular, in our work we used a saline solution containing less than $5 \%(\mathrm{v} / \mathrm{v})$ ethanol whereas other groups used a phosphate buffer solution $\left(0.1 \mathrm{~mol} \mathrm{dm}^{-1} ; \mathrm{pH}\right.$ 7.4) containing $10 \%(\mathrm{v} / \mathrm{v})$ ethanol $(2,3)$ or a saline solution containing $15 \%(\mathrm{w} / \mathrm{w})$ propylene glycol (18).

Subcellular distribution studies showed that $86.3 \% \pm$ $7.4 \%$ of ${ }^{99 \mathrm{~m}} \mathrm{Tc}(\mathrm{N})$-DBODC(5) was localized in the mitochondrial fraction, analogously to what was previously observed for ${ }^{99 \mathrm{~m}} \mathrm{Tc}$-sestamibi and ${ }^{99 \mathrm{~m}} \mathrm{Tc}$-tetrofosmin and supporting the conclusion that heart uptake occurs through an identical mechanism $(8,10,11)$. The presence of higher ${ }^{99 \mathrm{~m}} \mathrm{Tc}(\mathrm{N})$-activity in the cell fragments could be explained by the higher lipophilic character of ${ }^{99 \mathrm{~m}} \mathrm{Tc}(\mathrm{N})-\operatorname{DBODC}(5)$, compared with the commercial compounds.

Extraction of activity localized in the heart tissue after intravenous injection of the ${ }^{99 \mathrm{~m}} \mathrm{Tc}(\mathrm{N})$-complexes revealed that the myocardial uptake and trapping processes do not involve a change in the chemical nature of the tracer. Similarly, analysis of the identity of complexes extracted from urine samples and from the liver of female rats did not show any metabolic transformation. Sex-related differences 


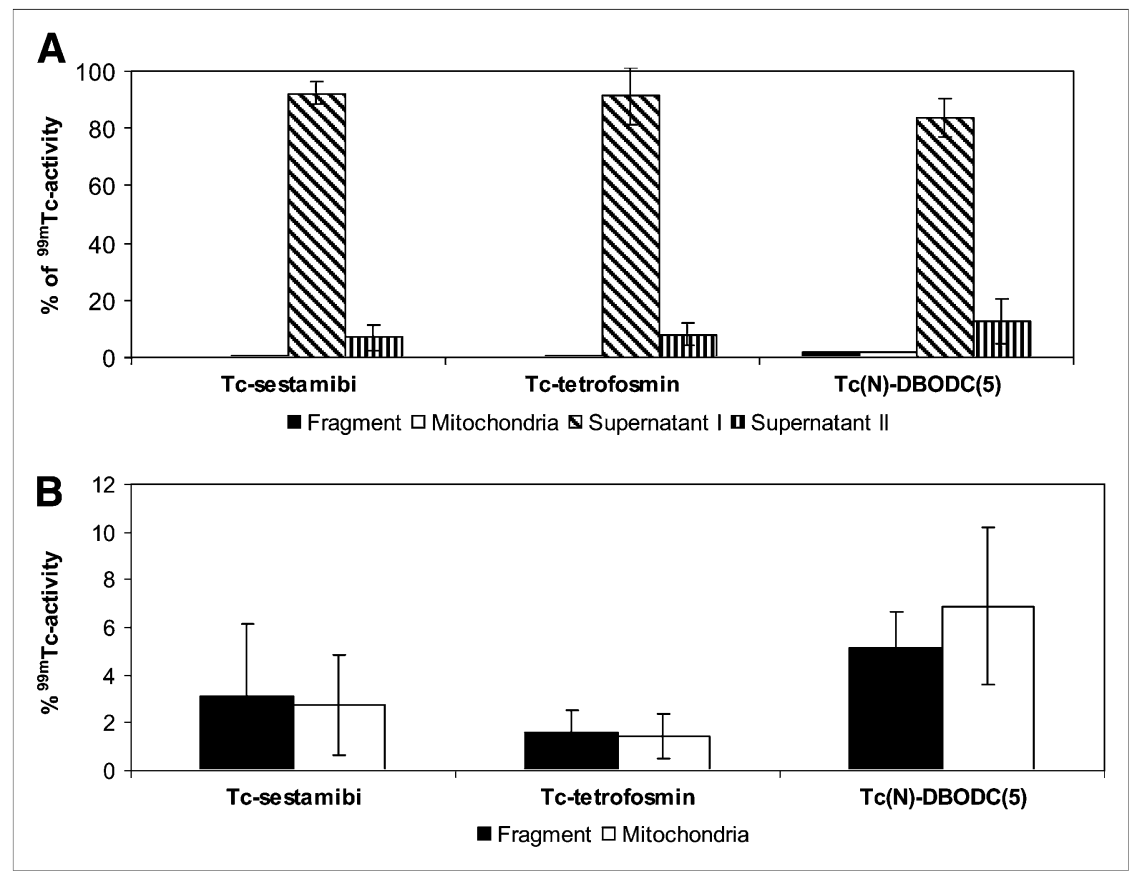

FIGURE 6. (A) Effects of CCCP $(5 \mu \mathrm{M})$ on ${ }^{99 m}$ Tc-activity content in each fraction. (B) CCCP-releasable ${ }^{99 m}$ Tc-activity in fragment and mitochondrial fraction.

were observed in the liver and in the endoluminal content of male rats, where a low amount of hydrophilic compounds was detected. This fact could be related to the expression of the hepatic CYP450 which is considerably higher in male than in female rats (12). Metabolic studies performed in vitro by incubating, at $37^{\circ} \mathrm{C}$, the purified ${ }^{99 \mathrm{~m}} \mathrm{Tc}(\mathrm{N})$-compounds in human serum, rat serum, and rat liver homogenates confirmed the high metabolic inertness of these compounds. These results displayed an irrelevant contribution of CYP450 enzymes to the pharmacokinetics of these agents, suggesting the participation of Pgp or MDR-Pgp in the efflux mechanism in ${ }^{99 m} \mathrm{Tc}(\mathrm{N})$-DBODC(5) from nontarget tissues.

Some evidence supporting the involvement of Pgp transporters in the pharmacokinetic profiles of these tracers was collected from biodistribution studies performed on female and male rats. In fact, biodistribution data showed a significantly reduced elimination of ${ }^{99 \mathrm{~m}} \mathrm{Tc}(\mathrm{N})$-DBODC(5) from the excretory organs of male rats, as compared with female rats. This finding is consistent with higher expression of Pgp/ MDR-Pgp proteins in female than in male rats $(12,13)$.

To confirm the role of these transporters in efflux of ${ }^{99 \mathrm{~m}} \mathrm{Tc}(\mathrm{N})$-agents from nontarget tissues, the effect of an MDR modulator, cyclosporin $\mathrm{A}$, on biodistribution of ${ }^{99 m} \mathrm{Tc}(\mathrm{N})-\mathrm{DBODC}(5)$ was investigated (19-22). When cyclosporin A was administered before intravenous injection of the tracer in female and male rats, ${ }^{99 \mathrm{~m}} \mathrm{Tc}(\mathrm{N})$-DBODC(5) uptake in lungs, liver, and kidneys was increased with respect to the baseline, and excretion from nontarget tissues was delayed, with a concomitant reduction of the corresponding target-to-nontarget ratios (Table 2). The most important differences were in the distribution of activity in the intestinal tract of female rats (Fig. 3), with a significant increase of activity in the intestinal tissue and a concomitant decrease in the endoluminal content. This fact strongly indicates that it is intestinal Pgps/MDR-Pgps, rather than metabolizing enzymes, that plays the most important role in

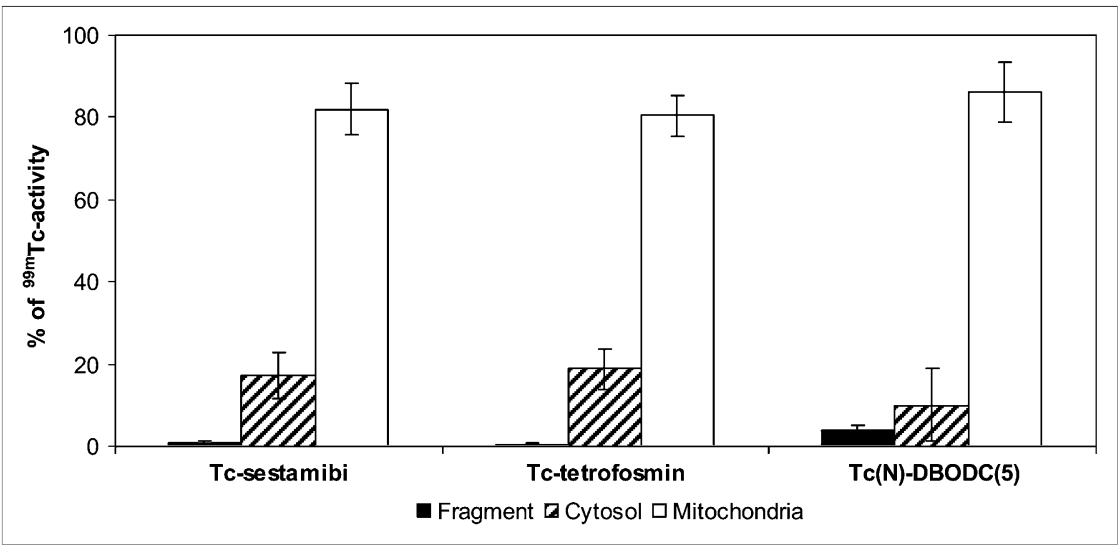

FIGURE 7. Corrected fractional subcellular distribution of $99 \mathrm{mTc}$-activity expressed as percentage of total activity. $99 \mathrm{~m}$ Tc-activity associated with malate dehydrogenase in supernatants I and II, or releasable by treatment of pellets with CCCP, was assigned to mitochondrial fraction. CCCP-insensitive ${ }^{99 m}$ Tc-activity in nonmitochondrial pellet was assigned to fragments, and all residual activity was assigned to cytosol. 
the prehepatic elimination of this compound (14). It is interesting to note that, after cyclosporin A treatment, heart activity was $30 \%$ higher than in the baseline studies (23).

All these changes were consistent with an enhanced intracellular concentration of the tracer due to inhibition of the Pgp function in healthy tissue by cyclosporin A.

Considering these results, it is reasonable to believe that the MDR Pgp transport function of hepatocytes and, in particular, of intestinal cells is responsible for the extremely fast efflux of ${ }^{99 \mathrm{~m}} \mathrm{Tc}(\mathrm{N})$-complexes from these regions. The difference in the excretion kinetics of ${ }^{99 \mathrm{~m}} \mathrm{Tc}(\mathrm{N})-\mathrm{DBODC}(5)$ with respect to ${ }^{99 \mathrm{~m}} \mathrm{Tc}$-sestamibi and ${ }^{99 \mathrm{~m}} \mathrm{Tc}$-tetrofosmin-a difference that results in significantly higher heart-to-liver ratios early after injection-could be justified by assuming that these ${ }^{99 \mathrm{~m}} \mathrm{Tc}(\mathrm{N})$-tracers can be recognized more specifically by the MDR-Pgps than the other two monocationic compounds. Consequently, it is reasonable to expect that these new compounds can be much more effective for noninvasive imaging of Pgp functions in different tumors (24-26).

\section{CONCLUSION}

The relevant finding of this study was the fact that the chemical identity of the ${ }^{99 \mathrm{~m}} \mathrm{Tc}(\mathrm{N})$-compounds was not modified in vivo by localization processes or by the action of enzymatic systems in different regions. The sex-related pharmacokinetic studies, including metabolism and excretion, as well as the effects of cyclosporin A strongly support the conclusion that the remarkably rapid efflux of ${ }^{99 \mathrm{~m}} \mathrm{Tc}(\mathrm{N})$-DBODC(3/5) from nontarget tissues cannot be attributed to metabolic transformations but is essentially due to the action of Pgp transporters.

The potential selective recognition of these ${ }^{99} \mathrm{~m} \mathrm{Tc}(\mathrm{N})-$ myocardial tracers as MDR-Pgp substrates, combined with their mitochondrial accumulation, may extend their clinical application from cardiology to oncology such as in tumor and MDR imaging studies. On the basis of these results, ${ }^{99} \mathrm{~m} \mathrm{Tc}(\mathrm{N})-\mathrm{DBODC}(5)$ could represent a first example for developing more specific and sensitive tumor markers.

\section{ACKNOWLEDGMENTS}

We are grateful to Prof Alessandro Dolmella for fruitful discussion and to Mariano Schiavon for his assistance in the biologic studies. We thank Nihon Medi-Physics Co., Ltd., Tokyo, Japan, for financial support of this work.

\section{REFERENCES}

1. Bolzati C, Refosco F, Cagnolini A, et al. Synthesis, solution-state and solid-state structural characterization of monocationic nitrido heterocomplexes $[\mathrm{M}(\mathrm{N})$ $(\mathrm{DTC})(\mathrm{PNP})]^{+}\left(\mathrm{M}={ }^{99} \mathrm{Tc}\right.$ and $\mathrm{Re} ; \mathrm{DTC}=$ dithiocarbamate; $\mathrm{PNP}=$ heterodiphosphane). Eur J Inorg Chem. 2004;9:1902-1913.

2. Boschi A, Bolzati C, Uccelli L, et al. A class of asymmetrical nitrido ${ }^{99 \mathrm{~m}} \mathrm{Tc}$ heterocomplexes as heart imaging agents with improved biological properties. Nucl Med Commun. 2002;23:689-693.
3. Boschi A, Uccelli L, Bolzati C, et al. Synthesis and biologic evaluation of monocationic asymmetrical ${ }^{99 \mathrm{~m}} \mathrm{Tc}$-nitride heterocomplexes showing high heart uptake and improved imaging properties. J Nucl Med. 2003;44:806-814.

4. Hatada K, Riou LM, Ruiz M, et al. ${ }^{99 \mathrm{~m} T c-N-D B O D C 5}$, a new myocardial perfusion imaging agent with rapid liver clearance: comparison with 99m Tc-sestamibi and 99mTc-tetrofosmin in rats. J Nucl Med. 2004;45:2095-2101.

5. Hatada K, Ruiz M, Riou LM, et al. Organ biodistribution and myocardial uptake, washout, and redistribution kinetics of Tc-99m N-DBODC5 when injected during vasodilator stress in canine models of coronary stenoses. $\mathrm{J} \mathrm{Nucl} \mathrm{Cardiol}$. 2006;13:779-790.

6. Cittanti C, Duatti A, Uccelli L, et al. ${ }^{99 \mathrm{~m}} \mathrm{TcN}-\mathrm{DBODC}$ : human biodistribution, dosimetry and safety of a new myocardial perfusion agent [abstract]. $\mathrm{J} \mathrm{Nucl}$ Cardiol. 2007;14(suppl):F21.

7. Tisato F, Refosco F, Bolzati C, et al. Intermediate compound of technetium nitride complex for radiodiagnostic imaging. International patent application no. PCT/JP2006/301260, pub. no. WO/2007/083395.

8. Carvalho PA, Chiu ML, Kronauge JF, et al. Subcellular distribution and analysis of technetium-99m-MIBI in isolated perfused rat hearts. J Nucl Med. 1992;33: 1516-1521.

9. Ochoa S. Malic dehydrogenase from pig heart. Methods Enzymol. 1955;1:735-739.

10. Platts EA, North TL, Pickett RD, Kelly JD. Mechanism of uptake of technetiumtetrofosmin I: uptake into isolated adult rat ventricular myocytes and subcellular localization. J Nucl Cardiol. 1995;2:317-326.

11. Younes A, Songadele JA, Maublant J, Platts E, Pickett R, Veyre A. Mechanism of uptake of technetium-tetrofosmin II: uptake into isolated adult rat heart mitochondria. J Nucl Cardiol. 1995;2:327-333.

12. Morris EM, Lee HJ, Predko LM. Gender differences in the membrane transport of endogenous and exogenous compounds. Pharmacol Rev. 2003; 55:229-240.

13. Suzuki T, Zhao YL, Nadai M, et al. Gender-related differences in expression and function of hepatic P-glycoprotein and multidrug resistance-associated protein (Mrp2) in rats. Life Sci. 2006;79:455-461.

14. Lin JH, Chiba M, Baillie T. Is the role of the small intestine in first-pass metabolism overemphasized? Pharmacol Rev. 1999;51:135-157.

15. Ford JM, Hait WN. Pharmacology of drugs that alter multidrug resistance in cancer. Pharmacol Rev. 1990;42:155-199.

16. Gatmaitan ZC, Arias IM. Structure and function of P-glycoprotein in normal liver and small intestine. Adv Pharmacol. 1993;24:77-97.

17. Fricker G, Miller DS. Relevance of multidrug resistance protein for intestinal drug absorption in vitro and in vivo. Pharmacol Toxicol. 2002;90:5-13.

18. Liu S, He Z, Hsieh WY, Kim Y. Evaluation of novel cationic ${ }^{99 \mathrm{~m}}$ Tc-nitrido complexes as radiopharmaceuticals for heart imaging: improving liver clearance with crown ether groups. Nucl Med Biol. 2006;33:419-432.

19. Chen CC, Meadows B, Regis J, et al. Detection of in vivo P-glycoprotein inhibition by PSC 833 using Tc-99m sestamibi. Clin Cancer Res. 1997;3:545552.

20. Kabasakal L, Halac M, Nisli C, et al. The effect of P-glycoprotein function inhibition with cyclosporine A on the biodistribution of Tc-99m sestamibi. Clin Nucl Med. 2000;25:20-23.

21. Agrawal M, Abraham J, Balis FM, et al. Increased ${ }^{99 m}$ Tc-sestamibi accumulation in normal liver and drug-resistant tumors after the administration of the glycoprotein inhibitor, XR9576. Clin Cancer Res. 2003;9:650656.

22. Peck RA, Hewett J, Harding MW, et al. Phase I and pharmacokinetic study of the novel MDR1 and MRP1 inhibitor biricodar administered alone and in combination with doxorubicin. J Clin Oncol. 2001;19:3130-3141.

23. Fojo AT, Ueda K, Slamon DJ, Poplack DG, Gottesman MM, Pastan I. Expression of a multidrug-resistance gene in human tumors and tissues. Proc Natl Acad Sci USA. 1987;84:265-269.

24. Schomcker K, Schicha H. Use of myocardial imaging agents for tumor diagnosis: a success story? Eur J Nucl Med. 2000;27:1845-1863.

25. Del Vecchio S, Salvatore MR. ${ }^{99 \mathrm{~m}} \mathrm{Tc}-\mathrm{MIBI}$ in the evaluation of breast cancer biology. Eur J Nucl Med Mol Imaging. 2004;31(suppl):S88-S96.

26. Sharma V. Radiopharmaceuticals for assessment of multidrug resistance P-glycoprotein-mediated drug transport activity. Bioconjug Chem. 2004;15: 1464-1474. 